\title{
Influence of "blooming" of Cyanobacteria in the Curonian lagoon on plankton test organisms
}

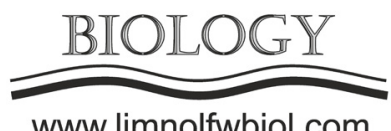

\author{
Semenova A.S.*, Dmitrieva O.A., Poddueva E.A. \\ Atlantic branch of the Russian Federal Research Institute of Fisheries and Oceanography "VNIRO" ("AtlantNIRO”), 5, Dmitry Donskoy \\ Str., Kaliningrad, 236022, Russia
}

\begin{abstract}
In 2017-2019 in the coastal zone of the Curonian lagoon, investigation of phytoplankton and zooplankton was carried out, as well as the effect of water from the Curonian lagoon on the survival and fertility of the test organisms Daphnia magna and Ceriodaphnia affinis in acute and chronic experiments was estimated. Samples were taken monthly from January to December. As a result, the toxic effect of "blooming" of Cyanobacteria and, as in particular, Microcystis spp. on plankton test organisms and zooplankton in general was observed. Water from the Curonian lagoon had the most negative impact on plankton test organisms and the zooplankton community from June to SeptemberOctober 2017-2018, as well as in August-September and November 2019.
\end{abstract}

Keywords: "blooming" of Cyanobacteria, Curonian lagoon, plankton test organisms, toxic effect, Microcystis spp.

\section{Introduction}

The Curonian lagoon is the biggest lagoon of the Baltic Sea with significant fishery and recreational importance. This reservoir may be defined as a highly productive area. The eutrophication processes here are strongly expressed due to the slow water change in the southern and central areas of the lagoon, shallow depths, and the silt accumulation in the bottom sediments. Cyanobacteria bloom is common for the summer and autumn period. The intensity and periods of these blooms exhibit strong interannual dynamics. The periods of maximal cyanobacteria bloom are observed for the warmest years. In hyper bloom periods (from July to September), potentially toxic species become abundant in the phytoplankton and account for $22-89 \%$ of the total phytoplankton biomass. Large accumulations of Cyanobacteria have a depressing effect on zooplankton organisms leading to its mortality. This study was aimed at analyzing the seasonal dynamics of the species composition, abundance, and biomass of phyto- and zooplankton communities, and studying influence of "blooming" of Cyanobacteria in the Curonian lagoon on plankton test organisms.

\section{Materials and methods}

The sampling was collected from January till December 2017-2019 every month at 2 standard stations in the shore area. The phyto- and zooplanktons were sampled from three water layers (from the bottom to the surface) using Van Dorn water sampler. Immediately after sampling, the zooplankton was stained with aniline blue to distinguish dead individuals from living ones (Seepersad and Crippen, 1978). After staining, the zooplankton samples were washed with water and preserved in $4 \%$ formaldehyde with sucrose. Laboratory processing was performed by the standard methods. In addition to phyto- and zooplankton samples, at one station, a water sample was taken once a month for biotesting on the test organisms Ceriodaphnia affinis Lilljeborg, 1901 and Daphnia magna Straus, 1820. Both acute and chronic experiments were carried out according to certified methods for determining water toxicity FR.1.39.2007.03221, FR.1.39.2011.09714, FR.1.39.2007.03222 and FR.1.39.2015.19999.

\section{Results and Discussion}

The acute toxic effect of water from the Curonian Lagoon, during which more than $50 \%$ of individuals died, were observed for Daphnia magna in June, July, September and October 2017 and from June to August 2018, for Ceriodaphnia affinis - in June, July and September 2017 and from June to August 2018. Chronic toxic effects, during which there was a decrease in fertility in the experiment compared with the control, for Daphnia magna - in August 2017, May 2018 and November 2019, for Ceriodaphnia affinis - in August and October 2017, May 2018 and August-September 2019. Chronic toxic effects, during which there was a

*Corresponding author.

E-mail address: a.s.semenowa@gmail.com (A.S. Semenova)

(C) Author(s) 2020. This work is distributed under the Creative Commons Attribution 4.0 License. 
stimulation of fertility in the experiment compared with the control, for Daphnia magna - in January-March and December 2017 February, April, and September 2018, May, October, and December 2019, for Ceriodaphnia affinis - in January-May and November 2017, January, February, April and September 2018, May-July 2019. Water from the Curonian Lagoon did not affect Daphnia magna - in April, May and November 2017, January, March and October 2018, April, June-September 2019, Ceriodaphnia affinis - in December 2017, March and October 2018, April, October December 2019. From November 2018 to March 2019, only acute experiments were carried out that showed no acute toxicity during this period for both test organisms Daphnia magna and Ceriodaphnia affinis.

Thus, water from the Curonian Lagoon had the strongest negative impact on plankton test organisms from June to September-October 2017-2018, as well as in August-September and November 2019; in other periods, the effect was stimulating or not noted. During periods when water from the Curonian Lagoon had the most negative toxic effect on the test organisms, a massive development of Cyanobacteria, and especially Microcystis spp., was noted, as in June-October 20172018 the biomass of Cyanobacteria was up to 34.5-51.2 $\mathrm{g} / \mathrm{m}^{3}$, the biomass of Microcystis spp. - up to 7.6-8.6 g/ $\mathrm{m}^{3}$.

Studies conducted in past years have shown that Microcystis spp. is toxic in the Curonian Lagoon and has the most negative effect on planktonic Cladocera (Semenova et al., 2017). The development of Microcystis spp. in 2019 was at a lower level, increasing its biomass was noted only in August 2019. In zooplankton during the period of mass development of Cyanobacteria, the proportion of dead individuals also increased, so from
June to October 2017, it varied from 11.3 to $14.7 \%$, from June to October 2018 - from 10.7 to $19.2 \%$, and in June-October 2019 only from 2.5 to $8.0 \%$, which indicates less toxicity of water from the Curonian lagoon in the summer-autumn 2019. In other months (from November to May), the proportion of dead individuals varied from 1.0 to $9.2 \%$, but usually did not exceed $5 \%$. A positive correlation of the proportion of dead individuals in zooplankton with biomass of Cyanobacteria and Microcystis spp. was noted.

\section{Conclusions}

Water from the Curonian lagoon had the most negative impact on planktonic test organisms and the zooplankton community from June to SeptemberOctober 2017-2018, as well as in August-September and November 2019; in other periods, the effect was stimulating or not was noted, during this period there was a massive development of Cyanobacteria and especially Microcystis spp., the toxicity of which apparently was one of the main causes of planktonic organisms death both in laboratory conditions and in nature.

\section{References}

Seepersad B., Crippen R.W. 1978. Use of aniline blue for distinguishing between live and dead freshwater zooplankton. Journal of the Fisheries Research Board of Canada 35: 13631366. DOI: $10.1139 / \mathrm{f} 78-213$

Semenova A.S., Sidelev S.I., Dmitrieva O.A. 2017. Experimental investigation of natural populations of Daphnia galeata G.O. Sars from the Curonian Lagoon feeding on potentially toxigenic Cyanobacteria. Biology Bulletin. 44: 538-546. DOI: 10.1134/S1062359017050156 